\title{
Interferon- and STING-independent induction of type I interferon stimulated genes during fractionated irradiation
}

Ruben S. A. Goedegebuure ${ }^{1,2 \dagger}$ (D), Esther A. Kleibeuker ${ }^{1 \dagger}$, Francesca M. Buffa ${ }^{3}$, Kitty C. M. Castricum ${ }^{4}$, Syed Haider ${ }^{3}$, Iris A. Schulkens ${ }^{1}$, Luuk ten Kroode ${ }^{4}$, Jaap van den Berg ${ }^{4}$, Maarten A. J. M. Jacobs ${ }^{5}$, Anne-Marie van Berkel ${ }^{6}$, Nicole C. T. van Grieken7, Sarah Derks ${ }^{1,2}$, Ben J. Slotman ${ }^{4}$, Henk M. W. Verheul ${ }^{8}$, Adrian L. Harris ${ }^{3}$ and Victor L. Thijssen ${ }^{4 *}$

\begin{abstract}
Background: Improvement of radiotherapy efficacy requires better insight in the dynamic responses that occur during irradiation. Here, we aimed to identify the molecular responses that are triggered during clinically applied fractionated irradiation.

Methods: Gene expression analysis was performed by RNAseq or microarray analysis of cancer cells or xenograft tumors, respectively, subjected to 3-5 weeks of $5 \times 2$ Gy/week. Validation of altered gene expression was performed by GPCR and/or ELISA in multiple cancer cell lines as well as in pre- and on-treatment biopsies from esophageal cancer patients (NCT02072720). Targeted protein inhibition and CRISPR/Cas-induced gene knockout was used to analyze the role of type I interferons and CGAS/STING signaling pathway in the molecular and cellular response to fractionated irradiation.

Results: Gene expression analysis identified type I interferon signaling as the most significantly enriched biological process induced during fractionated irradiation. The commonality of this response was confirmed in all irradiated cell lines, the xenograft tumors and in biopsies from esophageal cancer patients. Time-course analyses demonstrated a peak in interferon-stimulated gene (ISG) expression within 2-3 weeks of treatment. The response was accompanied by a variable induction of predominantly interferon-beta and/or -lambda, but blocking these interferons did not affect ISG expression induction. The same was true for targeted inhibition of the upstream regulatory STING protein while knockout of STING expression only delayed the ISG expression induction.
\end{abstract}

Conclusions: Collectively, the presented data show that clinically applied fractionated low-dose irradiation can induce a delayed type I interferon response that occurs independently of interferon expression or STING signaling. These findings have implications for current efforts that aim to target the type I interferon response for cancer treatment.

Keywords: Radiotherapy, Type I interferons, Immune response

\footnotetext{
* Correspondence: v.thijssen@amsterdamumc.nl

${ }^{\dagger}$ Ruben S. A. Goedegebuure and Esther A. Kleibeuker contributed equally to this work.

${ }^{4}$ Department of Radiation Oncology, Cancer Center Amsterdam, Amsterdam UMC, location VUmc, Amsterdam, The Netherlands

Full list of author information is available at the end of the article
}

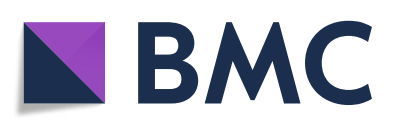

(- The Author(s). 2021 Open Access This article is licensed under a Creative Commons Attribution 4.0 International License, which permits use, sharing, adaptation, distribution and reproduction in any medium or format, as long as you give appropriate credit to the original author(s) and the source, provide a link to the Creative Commons licence, and indicate if changes were made. The images or other third party material in this article are included in the article's Creative Commons licence, unless indicated otherwise in a credit line to the material. If material is not included in the article's Creative Commons licence and your intended use is not permitted by statutory regulation or exceeds the permitted use, you will need to obtain permission directly from the copyright holder. To view a copy of this licence, visit http://creativecommons.org/licenses/by/4.0/. The Creative Commons Public Domain Dedication waiver (http://creativecommons.org/publicdomain/zero/1.0/) applies to the data made available in this article, unless otherwise stated in a credit line to the data. 


\section{Background}

Radiotherapy (RTx) remains a key modality of cancer treatment. For over a century, the clinical benefit of RTx has increased due to technical innovations that allow a more precise and targeted delivery of ionizing radiation to malignant tissues [1]. In addition, better insight in the biological and cellular response mechanisms to RTx has instigated the development of combination treatments that further improved the therapeutic outcome [2-4]. Many of the combination therapies comprise drugs that target tumor cell response mechanisms involved in radiotolerance or radioresistance $[5,6]$. The efficacy of such combination therapies depends on adequate dosescheduling and timing of the different treatment modalities [6]. To further improve combination radiotherapy, it is vital to better understand cellular and molecular responses and their time course during treatment. Gaining insight in the dynamic responses to radiotherapy is especially relevant for patients that are treated with a daily dose of irradiation for several weeks (conventional fractionated radiotherapy). Indeed, exploring molecular responses to irradiation has been recognized as an unmet need to develop rational approaches of combination radiotherapies [6].

While radiation-induced changes of gene expression have been explored previously [7-10], most studies have been aimed at identifying mechanisms that are involved in the development of acquired radioresistance. The induction of such a radioresistant phenotype usually requires irradiation schedules that are not commonly used in a clinical setting. Consequently, there is still only limited insight in the dynamics of cellular and molecular responses that actually occur during the time course of clinically applied low-dose fractionated irradiation. This lack of knowledge hampers the development and optimization of effective combination treatments with radiotherapy. Recently, we have shown that conventional fractionated RTx (daily 2 Gy irradiation, 5 days per week, up to 6 weeks) can induce a reversible radiotolerant phenotype in cancer cells in vitro; a response we coined as adaptive radioresistance. This response occurs in cancer cells of different origin and is characterized by convergence of clonogenic survival to a steady state level during treatment [11]. The observation that the surviving cells display the same radiosensitivity as non-irradiated cells following treatment suggests that cancer cells do not acquire radioresistance as a genetic trait. Possibly, a balance between cell death and repopulation occurs with cells adopting a phenotype that allows them to tolerate repetitive cycles of irradiation. This might represent a radioresistance mechanism with potentially clinical implications which urged us to further study the molecular pathways that are triggered during conventional low-dose fractionated irradiation.
Here, we report that clinically applied fractionated irradiation is accompanied by the induction of a type I interferon response which is characterized by the increased expression of interferon stimulated genes in vitro, in vivo and in esophageal cancer patients. Importantly, the observed response occurs independently of induction of specific type I/III interferon expression or upstream activation of the STING signaling pathway. Our findings have implications for current efforts to develop drugs that target the type I interferon response and warrant further investigation into the role of the type I interferons and interferon stimulated genes during fractionated radiotherapy.

\section{Methods}

\section{Cell culture}

The high-grade astrocytoma cell line D384 (grade III), colorectal cancer cell lines HT29, RKO, SW480, COLO320 and HCT116 and esophageal cancer cell line OE19 were cultured in Dulbecco's Modified Eagle Medium (DMEM), supplemented with $10 \%$ fetal calf serum, $100 \mathrm{IU} / \mathrm{mL}$ penicillin and $100 \mu \mathrm{g} / \mathrm{mL}$ streptomycin. Cells were maintained at $37^{\circ} \mathrm{C}$ and $5 \% \mathrm{CO} 2$ under humidified conditions. Cell lines were authenticated by STR profiling (BaseClear, Leiden, The Netherlands) and were repeatedly found negative for mycoplasm infection as checked by PCR.

\section{In vitro and in vivo irradiation}

Irradiation of cultured cells in vitro was performed with $\gamma$-radiation using a ${ }^{60} \mathrm{Co}$ source $(2.80 \mathrm{~Gy} / \mathrm{min}$; Gammacell 200; Atomic Energy of Canada, Mississauga, Ontario, Canada) or a ${ }^{137} \mathrm{Cs}$ laboratory irradiator $(0.81 \mathrm{~Gy} /$ min; IBL 637, CIS Bio International). Cells were irradiated with a daily dose of 2 Gy from Monday till Friday for up to 6 weeks, i.e., a maximum of $30 \times 2 \mathrm{~Gy}$ ). Culture medium was refreshed every Monday. At the end of each treatment week, culture medium was collected and cells were harvested and stored at $-80^{\circ} \mathrm{C}$ until further analysis. All experiments were performed in triplicate unless indicated otherwise.

Irradiation of xenograft HT29 tumor in nude mice were carried out as published previously [12]. In brief, $5 \times 10^{6}$ HT29 cells in $100 \mu \mathrm{L}$ Matrigel/DMEM suspension were injected subcutaneously in the lower right flank of 6- to 7-week-old female BALB/c nude mice. Tumor growth was monitored 3-4 times per week measuring the tumor length (L), width (W), and height (H) with calipers. Tumor volume was calculated as 1/ $6 * \pi^{*} \mathrm{~L}^{*} \mathrm{~W} \mathrm{~W}^{*} \mathrm{H}$. When the average tumor size reached a volume of approximately $100 \mathrm{~mm}^{3}$, the mice were randomized into experimental groups. Irradiated mice received daily 2 Gy fractions from Monday to Friday using an Xstrahl RS320 X-Ray irradiator (Xstrahl Ltd. UK). For 
this, mice were anesthesized by i.p. injection of $100 \mu \mathrm{L} 1$ : 1:8 hypnorm: hypnovel: sterile water after which they were placed in $\pm 12 \mathrm{~mm}$ thick lead tubes with only the tumor exposed for irradiation. Following treatment, tumor tissues were collected, snap frozen and stored at $-80^{\circ} \mathrm{C}$ until further analysis.

\section{Patient material}

Snap frozen and formalin-fixed paraffin embedded primary tumor biopsies from esophageal cancer patients receiving neoadjuvant chemoradiation (paclitaxel, carboplatin and concurrent radiotherapy of $41.4 \mathrm{~Gy}$ in 23 fractions) were collected via endoscopy as part of an IRB-approved clinical trial (NCT02072720, METC-VUmc identifier 2013.340). Tumor biopsies were collected at baseline and during treatment, either after 1, 2, 3 or 4 weeks depending on the study cohort. Histology from all obtained biopsies was assessed by an expert pathologist $(\mathrm{NvG})$. Pre-treatment biopsies were included when tumor cell percentage was $>20 \%$. As during treatment samples could be extensively affected by radiotherapy induced tumor necrosis, accurate assessment of tumor cell was not feasible. Instead, these biopsies were obtained with extra care from a representative area on the tumor border by an expert gastroenterologist.

\section{RNA extraction and qPCR}

RNA isolation from mouse xenografts tumors and cultured cells for RNA sequencing analysis was performed using the mirVANA kit (Life technologies), excluding the purifying miRNA step. For all other RNA isolations, TRIzol (Invitrogen) was used according to the supplier's protocol, using chloroform for phase separation and isopropanol to precipitate the RNA. The final RNA concentration was determined using the Nanodrop ND-1000. Subsequent reverse transcription was performed on $1 \mu \mathrm{g}$ RNA using the iScript kit (Biorad) following the suppliers' protocol. cDNA was stored at $-20^{\circ} \mathrm{C}$ until further use. qPCR was performed using $1 x$ SYBR green supermix (Biorad), $1.5 \mu \mathrm{L} c \mathrm{cNA}$ and $400 \mathrm{nM}$ primers in a total sample volume of $25 \mu \mathrm{L}$. For normalization, the primers targeting reference genes $\beta$-actin (F: TTCCTA TGTGGGCGACGAG R: TCCTCGGGAGCCACACG), HPRT (F: TGCTGAGGATTTGGAAAGG R: TCACAT CTCGAGCAAGACGT) and cyclo-A (F: AGCATGTG GTGTTTGGCAAA R: TCGAGTTGTCCACAGTCAGC ) were used unless stated otherwise. All other primer sequences are listed in Supplementary Table 1. qPCR was performed in a CFX96 cycler (Biorad) and the following cycling conditions were used: $95^{\circ} \mathrm{C}$ for $5 \mathrm{~min}$, followed by 40 cycles of $95^{\circ} \mathrm{C}$ for $10 \mathrm{~s}$ and $60^{\circ} \mathrm{C}$ for $30 \mathrm{~s}$, after which standard meltcurve analysis was performed.

\section{mRNA sequencing and data analysis}

Approximately $1 \mu \mathrm{g}$ total RNA was normalized and enriched using the NEBNext PolyA mRNA Magnetic Isolation Module (New England Biolabs) with a final elution in $18 \mu \mathrm{L}$, to feed into the NEBNext mRNA Library Prep Master Mix Set for Illumina (New England Biolabs) with the following modifications: post fragmentation purification was a RNA Clean Ampure XP (Agencourt) magnetic bead clean-up (2.8x volume) with $3 \times 80 \%$ ethanol washes and a final elution in $15 \mu \mathrm{L}$ buffer $\mathrm{EB}$ (QIAGEN). The first strand reverse transcription was conducted following protocol, but with the addition of Actinomycin D $(0.05 \mu \mathrm{g} / \mu \mathrm{l}$ final concentration). The second strand reverse transcription followed the E7490 protocol, but the reaction buffer was replaced with NEBNext $^{\oplus}$ Second Strand Synthesis (dNTP-free) Reaction Buffer (New England Biolabs) and a dNTP mix containing $A, C, G, U$ at $0.3 \mathrm{mM}$ for each final concentration. Double strand cDNA purification was done using Ampure XP magnetic bead clean-up (1.2x volume). End repair, A-tailing and adapter ligation were conducted following protocol with $1.8 \mathrm{x}$ volume Ampure XP cleanups between steps. The PCR amplification was performed following protocol with $2 \mu \mathrm{L} \mathrm{H} 2 \mathrm{O}$ being replaced with $2 \mu \mathrm{L}$ USER enzyme and the Phusion polymerase being added after a $37^{\circ} \mathrm{C}$ incubation for $30 \mathrm{~min}$. A subsequent 12 cycles of PCR were performed using custom PCR primers [13]. Post-PCR libraries were quantified with Picogreen (Invitrogen) and size range determined using the Tapestation D1K (Agilent). Libraries were pooled equimolarly with a final quantification by $\mathrm{qPCR}$ before sequencing. Then, quality control was performed using FASTQC version 0.11.2. Subsequently, data filtering such as removal of technical sequences (e.g. adaptors), duplicate reads, and secondary reads were performed using Prof. Buffa's laboratory pipelines. Quality control task was performed again after the data filtering procedures to double confirm the quality. The clean short reads were aligned to human reference genome GRCH37 using tophat2 version 2.0.13. The library type in tophat 2 was set to fr-firststrand, which specified the right-most end of fragment is the first sequenced. The expected inner distance between mate pairs is set to --mate-inner-dist $=90$. After that, the differential expression of each gene was estimated by cuffdiff version 2.2.1. The setting of library type is fr-firststrand, which is the same with the setting in tophat2. In the end, the consistently up-regulated genes and down-regulated genes, based on statistics of rank product, among samples are generated. The $\mathrm{R}$ library of Rank Product is version 2.40.0. The $p$-value and the probability of false positive of gene rank were estimated by a resampling technique with 100 random permutations. 


\section{Microarray gene expression and data analysis}

High-density oligonucleotide Expression BeadChips (Human HT12_V4, Illumina) were used for whole GenomeWide gene expression profiling, for 3 to 4 biological replicates. In brief, $500 \mathrm{ng}$ of total RNAs were reverse transcribed to synthesize first- and second- strand cDNA, purified and in vitro transcribed to synthesize biotinlabeled cRNA using the Illumina TotalPrep-96 RNA Amplification Kit (Ambion). A total of 1500 ng of biotinlabeled cRNA was then hybridized to the BeadChips at $55^{\circ} \mathrm{C}$ for $18 \mathrm{~h}$. The hybridized BeadChip was washed and stained with streptavidin-Cy3 according to the manufacture protocols using Illumina whole-genome gene expression direct hybridization assay (Illumina). GenomeStudio Data Analysis Software was used to visualize and analyze images generated. The Illumina microarrays were preprocessed using $\mathrm{R}$ package LIMMA (v3.16.8). Briefly, background correction was performed using negative controls, followed by quantile normalization and $\log 2$ transformation. Any probes whereby all samples had detection $p$-value $\geq 0.05$ were regarded as not-expressed and subsequently removed from the dataset. Paired analysis was performed, as at least 3 matched samples were available in each group. Gene ontology enrichment analyses of differentially expressed genes were conducted using $\mathrm{R}$ package GOstats (v2.26.0). All visualizations and statistical analyses were performed in R statistical environment (v4.0.2).

\section{Elisa}

Enzyme-linked immunosorbent assays were performed according to the manufacturer's instructions (R\&D systems, Abingdon, UK). Expression levels were normalized to the number of cells for the in vitro experiments and to the total protein level for the tumor xenografts.

\section{Clonogenic survival assay}

Clonogenic survival assays were determined as described before [11]. In brief, cells were collected at different time points during the treatment period and 10.000 to 100.000 cells were plated in duplicate in T25 culture flasks and cells were grown for 14 days under normal culture conditions. At the end of each experiment, cells were fixed with $100 \%$ ethanol for $30 \mathrm{~min}$, and stained with Giemsa solution (Merck, Darmstadt, Germany). Colonies ( $>50$ cells) were counted visually and plating efficiency (PE) was calculated by dividing the number of colonies counted by the number of cells plated. Surviving fractions (SF) were calculated by dividing the PE of irradiated cells by the PE of the non-irradiated controls.

\section{Statistical analysis}

For the statistical analyses of mRNA sequencing and micro-array studies, please refer to the specific method description. Differences in mRNA and protein expression were tested for statistical significance with either the nonparametrical Wilcoxon signed rank test or Mann-Whitney $\mathrm{U}$ test for comparison of paired or independent observations in 2 groups, respectively. For multiple groups or time-course comparisons a Kruskal-Wallis test with Bonferroni post-hoc test was performed. For the comparison of HT29 xenograft tumor volumes a 2-way ANOVA with Bonferroni post-hoc test was performed. A $p$-value $\leq 0.05$ was considered as statistically significant. Statistical analyses were performed using GraphPad Prism 8.0.0, GraphPad Software, San Diego, California US.

\section{Results}

To identify the molecular mechanism(s) involved in the response to conventional fractionated irradiation, we set out to compare gene expression profiles in irradiated vs. non-irradiated cells. For this, HT29 colorectal carcinoma cells were subjected to a common clinically applied treatment schedule of daily 2 Gy irradiation, 5 days per week for up to 5 weeks (Fig. 1a). Since our previous work showed that clonogenic survival converges to a steady state after 2 weeks of treatment, i.e. 10 fractions (Fig. 1b), we first compared the expression at that timepoint with the expression in non-irradiated cells, cultured identically for 2 weeks. Gene expression analysis by RNA sequencing identified over a thousand differentially expressed genes (adjusted $p$-value $\leq 0.05$ ) in irradiated vs. non-irradiated cells (Fig. 1c and Supplementary Tables $2+3)$. Gene ontology (GO) analysis revealed over 250 significantly enriched upregulated biological processes, amongst which the 'type I IFN-mediated signaling pathway' was identified as the most significantly enriched biological process (adjusted $p$-value $\leq 0.0001$ ) (Supplementary Fig. S1a and Supplementary Table 4). Other identified GO terms were closely related to biological processes such as positive regulation of cell migration, angiogenesis, negative regulation of cell proliferation, amine metabolism, response to virus and nucleosome assembly. Additionally, over a hundred significantly enriched downregulated biological processes were identified, mainly related to translational processes and cell cycle (Supplementary Fig. S1b). Given the current insights in radiotherapy-induced type I interferon signaling $[14,15]$, as well as previous (pre) clinical trials on the combination of radiotherapy with type I interferons in cancer [16], we further focused our research on this particular response.

The induction of the type I IFN response in HT29 cells could be confirmed by qPCR with a panel of 10 interferon stimulated genes (ISGs) that are linked to this response (Fig. 1d). Moreover, the increased expression of ISGs by $10 \times 2$ Gy irradiation could be confirmed in multiple cancer cell lines, including high-grade astrocytoma cells (D384) and different colorectal cancer cell 

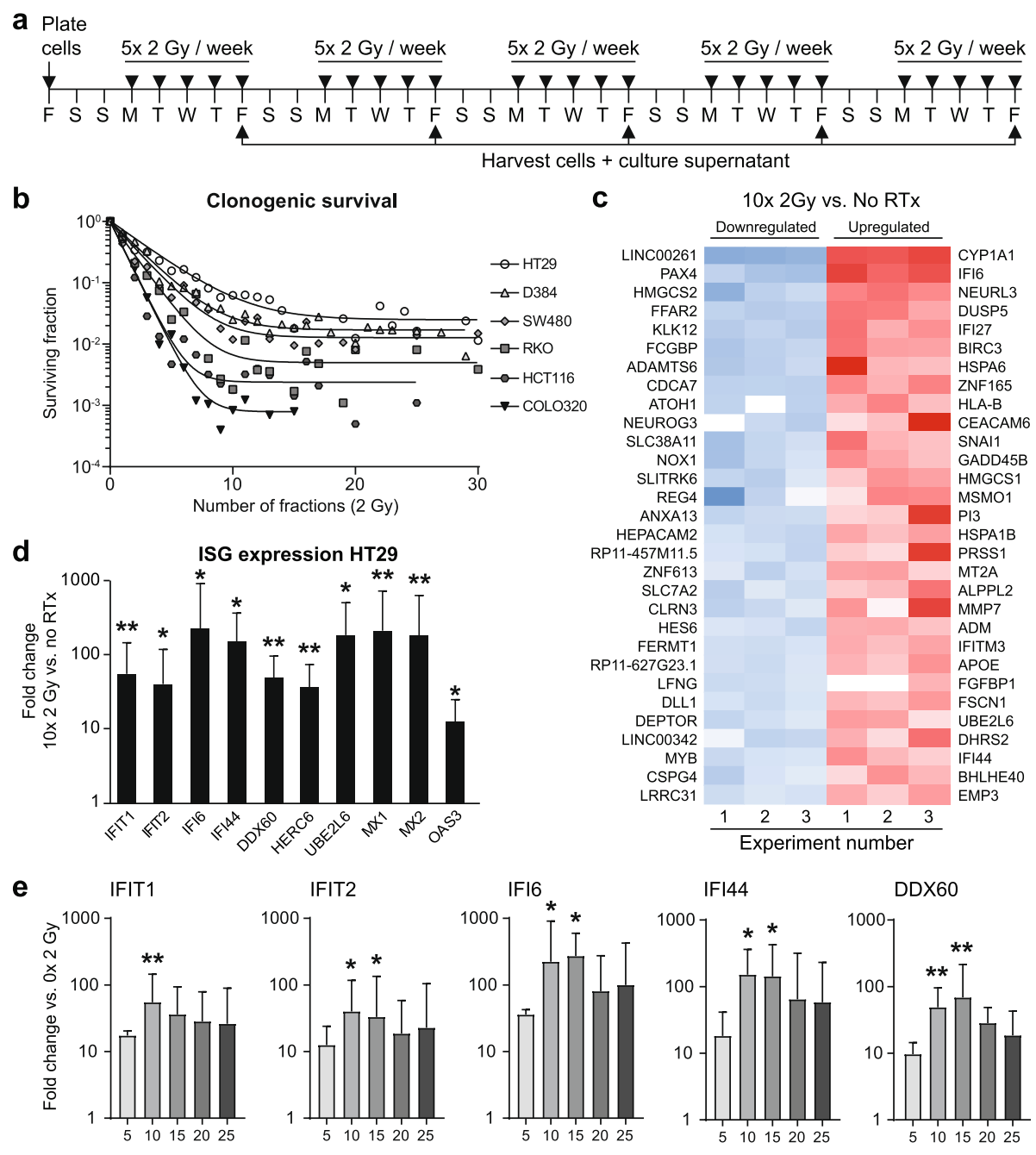

DDX60
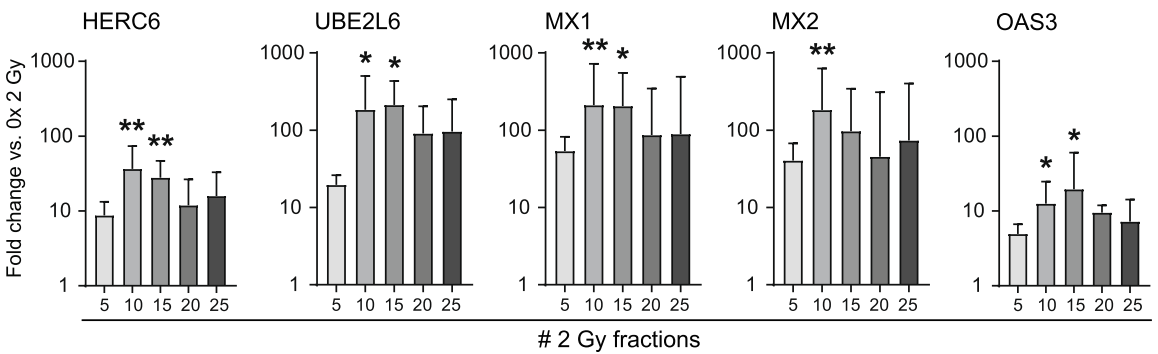

Fig. 1 Induction of a type I IFN response in cancer cells peaks after 2 weeks of fractionated irradiation in vitro. Fractionated irradiation induces a type I IFN response in cancer cells, which peaks after 2 weeks and coincides with a convergence in clonogenic survival to a steady state. a Scheme of fractionated irradiation applied to human cancer cells in vitro. $\mathbf{b}$ Clonogenic survival analyses show a log-linear decline in survival during the first 2 weeks of treatment after which a steady-state survival is reached up to 6 weeks of treatment. Adapted from Van den Berg et al. [1 1]. c Heat map showing the 30 most downregulated and upregulated genes after 2 weeks of treatment vs. untreated as determined by RNA deep-sequencing of HT29 cells $(n=3)$. $\mathbf{d}$ The mRNA expression induction of a panel of 10 IFN-stimulated genes (ISGs) after 2 weeks of treatment was confirmed by qPCR $(n=3)$. Geometric mean $+S D$ is shown. * $p$-value $\leq 0.05$ vs. no radiotherapy (RTx). e Time course analysis of ISG mRNA expression induction shows a peak starting around 2 weeks of treatment $(n=3)$. Geometric mean $+\mathrm{SD}$ is shown. ${ }^{*} p$-value $\leq 0.05$ vs $0 \times 2 \mathrm{~Gy}$

lines (SW480, HCT116, COLO320, RKO; Supplementary Fig. S2). To determine the dynamics of the response, the ISG expression was analyzed weekly for up to 5 weeks. This showed a slight induction in expression for most
ISGs after 5 fractions, and a peak induction after 2 to 3 weeks of treatment (Fig. 1e and Supplementary Fig. S3a). Continuation of RTx eventually resulted in a decreased expression, although it generally remained above the 
level of non-irradiated cells. Of note, while single dose irradiation also induced dose-dependent ISG expression, this typically leveled off after 6 Gy (Supplementary Fig. S3b). Collectively, these data show that fractionated RTx induces an intrinsic type I interferon response in vitro which peaks within 2 to 3 weeks of treatment and coincides with the development of a steady state in clonogenic survival.

To extend these findings, HT29 xenograft tumors were locally irradiated using the same clinical schedule as the cultured cells, i.e., 2 Gy per day, 5 days per week for up to 3 weeks (Fig. 2a). Tumor growth showed a delay after 2 weeks of treatment but appeared to recover in week 3 (Fig. 2b and Supplementary Fig. S4a). Next, gene expression profiles of non-irradiated tumors vs. tumors that received 1, 2 and 3 weeks of radiotherapy were obtained using human microarray analysis. After 2 weeks of treatment, 34 differentially expressed genes in irradiated vs. non-irradiated tumor tissues were identified, of which 5 showed decreased expression and 29 showed increased expression (Fig. 2c, Supplementary Table 5). Gene ontology analysis revealed 52 significantly enriched biological processes, amongst which the 'type I IFN-mediated signaling pathway' was again identified as the most significantly enriched pathway ( $p$-value $\leq 0.0001$, count $18 / 61$ ) (Supplementary Fig. S4b and Supplementary Table 6). Interestingly, a less pronounced but similar gene expression profile was observed after 1 and 3 weeks of irradiation, whereas a single dose of $5 \mathrm{~Gy}$ resulted in more differentially expressed genes (Supplementary Fig. S4c). Expression analysis of the same ISG signature panel as used before, again confirmed the induction of a type I IFN response (Supplementary Fig. S4d). Moreover, in line with our observations in the cell lines, time course analysis revealed that the expression of the ISGs peaked after 2 to 3 weeks of treatment (Fig. 2d). Altogether, these results show that fractionated RTx induces a potent type I interferon response in tumor cells after 2 to 3 weeks of treatment.

To determine which type I IFN could have triggered the response, we analyzed the mRNA expression of two key family members in vitro, i.e., IFN alpha $(I F N-\alpha)$ and IFN beta $(I F N-\beta)$. Since type III interferons (IFN lambda; IFN- $\lambda$ ) were recently shown to be induced by RTx in HT29 [17], these cells were included as a positive control. Analysis of fractionally irradiated HT29 tumor cells revealed that the treatment predominantly induced the mRNA expression and protein secretion of IFN- $\beta$ and IFN- $\lambda$ (Fig. 3a+b). Other cell lines subjected to fractionated irradiation displayed either a modest increase in mRNA expression of either IFN- $\alpha, I F N-\beta, I F N-\lambda$ or a combination (HCT116 and RKO), or no interferon induction at all (SW480 and Colo320) (Fig. 3c). Interestingly, all of these cell lines showed clear induction of
ISG expression in response to irradiation, albeit less profound in the cell lines lacking interferon expression (Supplementary Fig. S2). In the xenograft tumors, no changes in the expression of any of the different interferons could be detected (Fig. 3d+e). These findings suggest an uncoupling between the induction of ISGs and the expression of interferons, the latter usually mediating ISG expression. Of note, all the cell lines expressed the appropriate IFN receptors required to be responsive to the different IFNs (Supplementary Fig. S5).

To assess the clinical relevance of these findings, we analyzed whether a type I IFN response occurs in cancer patients, in the context of a clinical pilot study (NCT02072 720 ) in esophageal cancer patients receiving neoadjuvant chemoradiotherapy (CRT) with paclitaxel, carboplatin and concurrent radiotherapy (41.4 Gy in 23 fractions of 1.8 Gy). Tumor biopsies of 20 patients (see Supplementary Table S7 for patient characteristics) were collected at baseline and after 1, 2, 3 or 4 weeks of treatment, in successive cohorts. Subsequent expression analysis revealed that expression levels of 5 out of 7 investigated ISGs were significantly elevated during treatment as compared to baseline (Fig. 3f). Of note, while the number of patients in this small pilot study did not allow us to confirm an association between pre-treatment ISG expression levels and response to treatment $[18,19]$, we did observe ISG expression levels were highest in patients that had received 2 weeks of treatment (Supplementary Fig. S6a). The latter is in line with our findings in tumor cells and xenograft tumors. Furthermore, a modest induction of all interferons was seen (significant for IFN- $\beta$ and IFN- $\lambda 2 / 3$; Fig. $4 \mathrm{~g}$ ), but again ISG expression appeared to occur independent of type I interferons, as only a weak correlation was observed between induction of IFN- $\beta$ and 3 out of 7 ISGs (Supplementary Fig. S6b). Thus, both in a preclinical immunocompromised xenograft model as well as in a clinical setting, commonly applied fractionated irradiation triggers a type I interferon response independent of actual type I interferon expression induction.

Since the induction of a type I interferon response during radiotherapy has been linked to cGAS/STING signaling $[14,20,21]$, we further evaluated the role of STING as well as of interferon expression on the induction of ISGs during fractionated irradiation. Analysis of both mRNA and protein expression showed low or even absent basal expression of cGAS, STING or both in the majority of cell lines, except for HT29 (Fig. 4a+b). Since all cell lines did show elevated ISG expression during fractionated irradiation, these findings suggest that the radiation-induced type I interferon response does not depend on cGAS/STING signaling. Of note, when cells that were deficient in either cGAS or STING were irradiated, the expression of the absent proteins was not induced (Supplementary Fig. S7a). 

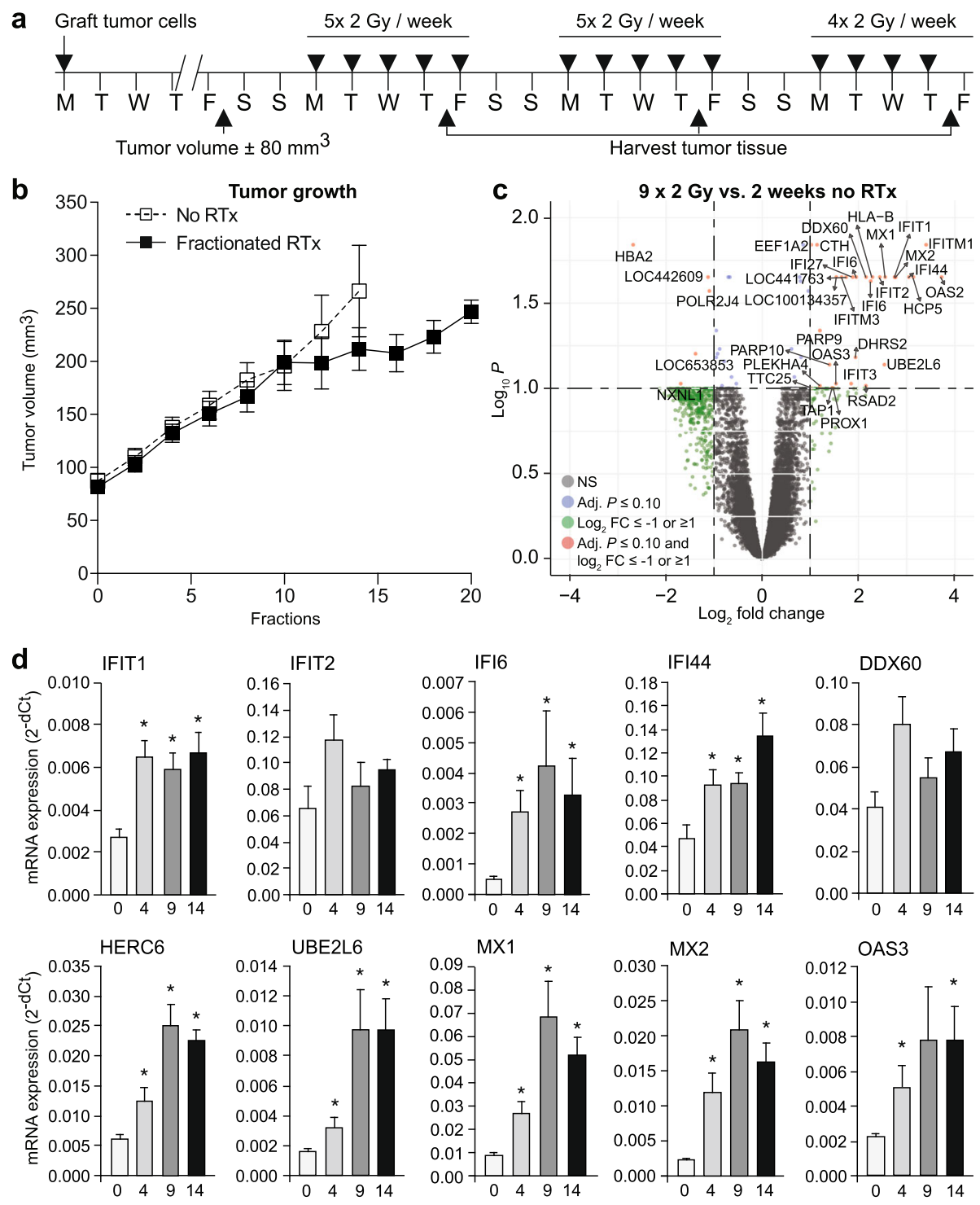

\# 2 Gy fractions

Fig. 2 Induction of a type I IFN response in tumor tissue peaks after 2 weeks of fractionated irradiation in vivo. The induction of a type I IFN response upon fractionated radiotherapy is confirmed in a HT29 xenograft model. a Scheme of fractionated irradiation applied to HT29 xenograft tumor in mice. b Tumor growth curves of HT29 xenograft tumors with (black squares) or without (white squares) irradiation. Note the growth delay starts around day 10 and recovers around day 17 ( $n=5$ mice/group). c Volcano plot of microarray data comparing gene expression in HT29 xenograft tumors after 2 weeks of RTx vs. no radiotherapy (RTx). NS = not significant. FC = fold change. $\mathbf{d}$ Time course analysis of ISG mRNA expression induction shows a gradual increase that peaks around 2 weeks of treatment. * $p$-value $\leq 0.05$ vs. $0 \times 2$ Gy

To further study the disconnection between the radiation-induced type I interferon response and cGAS/ STING activation or type I interferon expression, we irradiated HT29 cells (which express all components of the pathway) in the presence of either anti-IFN- $\beta$ antibody, anti-IFN- $\lambda$ antibody or a STING antagonist. Optimal antibody treatment conditions were based on literature [16] and the levels of IFN- $\beta$ and IFN- $\lambda$ in cell culture supernatants. In addition, direct effects of treatment on cell viability were excluded (Supplementary Fig.
S7b). Also, the inhibitory function of the STING antagonist was confirmed by Western blot showing reduced phosphorylation of the downstream target protein Tank Binding Kinase (pTBK) after 4Gy irradiation as compared to no irradiation (Supplementary Fig. S7c). In line with our previous observations, neither treatment with anti-IFN antibodies nor treatment with the STING antagonist had any effect on the induction of ISG or IFN expression during fractionated irradiation (Fig. 4c). Moreover, neither treatment affected the clonogenic 

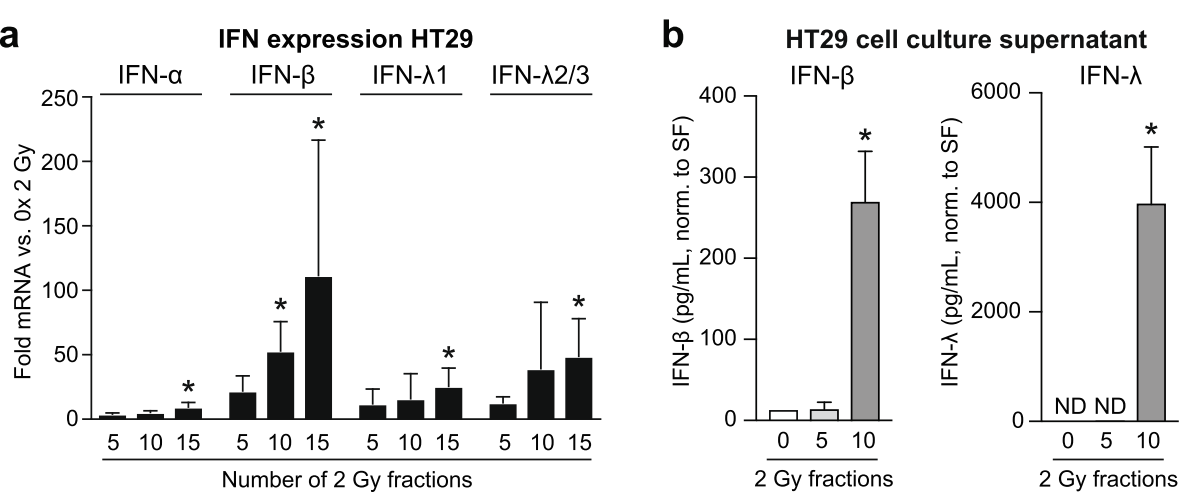

C
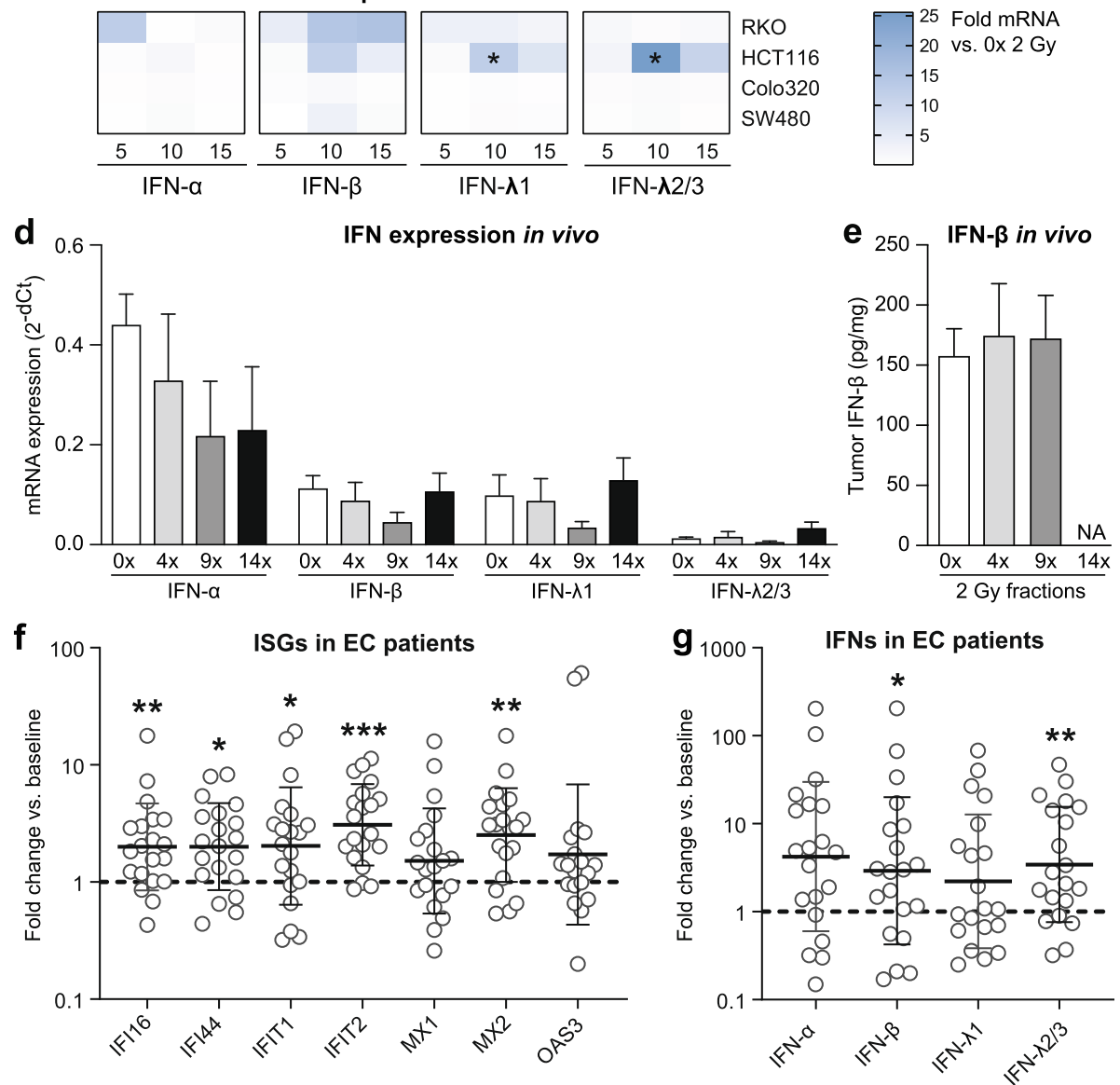

Fig. 3 Patterns of type I and III interferon induction upon fractionated irradiation. Different patterns of either type I and/or type III interferon induction occur in vitro, in vivo and patients with esophageal cancer during the course of fractionated radiotherapy, independent of ISG induction. a mRNA expression analyses of interferon expression in HT29 cells during fractionated irradiation $(n=3)$. * $p$-value $\leq 0.05$ vs. $0 \times 2$ Gy. $\mathbf{b}$ Levels of IFN- $\beta$ and IFN- $\lambda$ protein in cell culture supernatants of $\mathrm{HT} 29$ cells during fractionated irradiation $(n=3)$. ${ }^{*} p$-value $\leq 0.05$ vs. $0 \times 2 \mathrm{~Gy}$. $\mathrm{CM}=$ culture medium. SF $=$ surviving fraction. $\mathbf{c}$ mRNA expression analyses of interferon expression in RKO, HCT116, COLO320 and SW480 cells during fractionated irradiation vs. $0 \times 2$ Gy. ${ }^{*} p$-value $\leq 0.05$ vs. $0 \times 2$ Gy. d mRNA expression analyses of interferon expression in HT29 xenograft tumors during fractionated irradiation ( $n=5$ mice/group). e Levels of IFN- $\beta$ and IFN- $\lambda$ protein in mouse serum during fractionated irradiation ( $n=5$ mice/group). $\mathbf{f}$ mRNA expression levels of ISG expression in patient-matched tumor samples from esophageal cancer patients $(n=20)$ prior to or during chemoradiotherapy. Fold expression in on-treatment samples vs. pre-treatment is shown. ${ }^{*} p$-value $\leq 0.05$ vs. matched pre-treatment samples. g Similar as in (f) for fold change in mRNA expression levels of different IFNs. * $p$-value $\leq 0.05$ vs. matched pre-treatment samples

survival of HT29 cells prior to irradiation (Supplementary Fig. S7d) or during fractionated irradiation (Fig. 5 d). This was not due to lack of treatment efficacy, since
anti-IFN $\beta$ antibody treatment did neutralize the known inhibitory effect of IFN- $\beta$ on cell growth (Supplementary Fig. S7e). Again, these data suggest that the type I IFN 


\section{a}

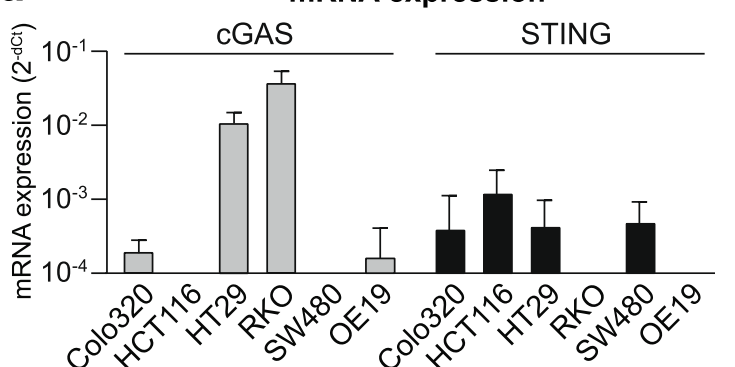

C

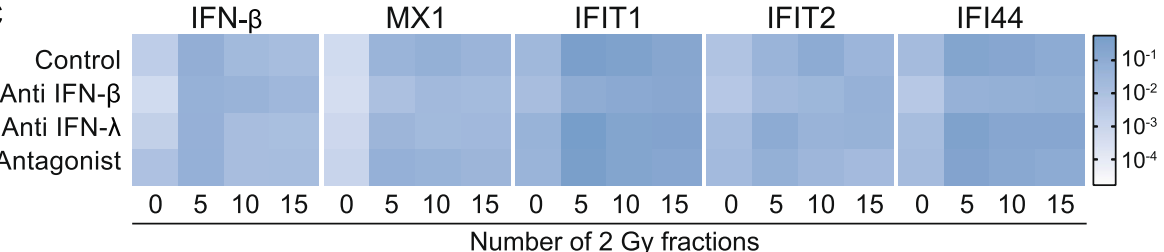

d

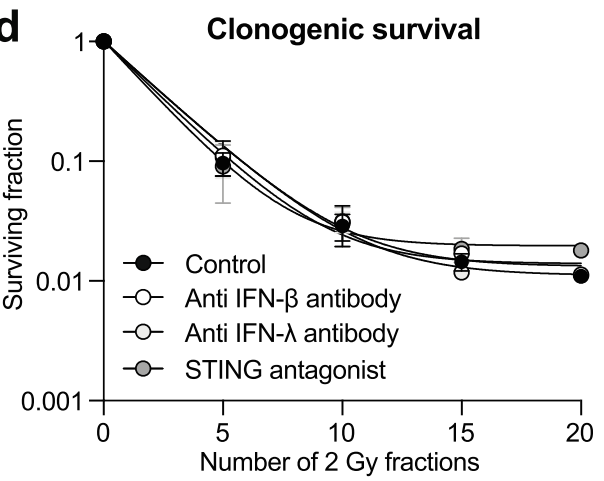

\section{f}

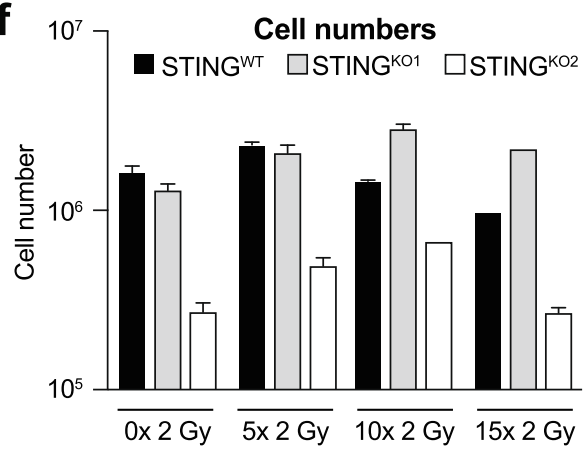

b Protein expression

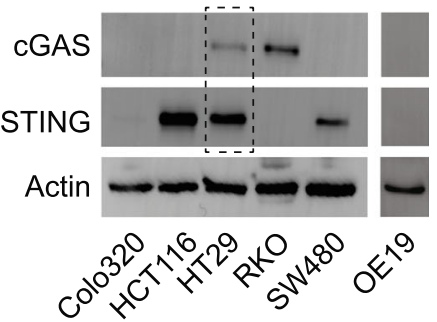

IFIT2
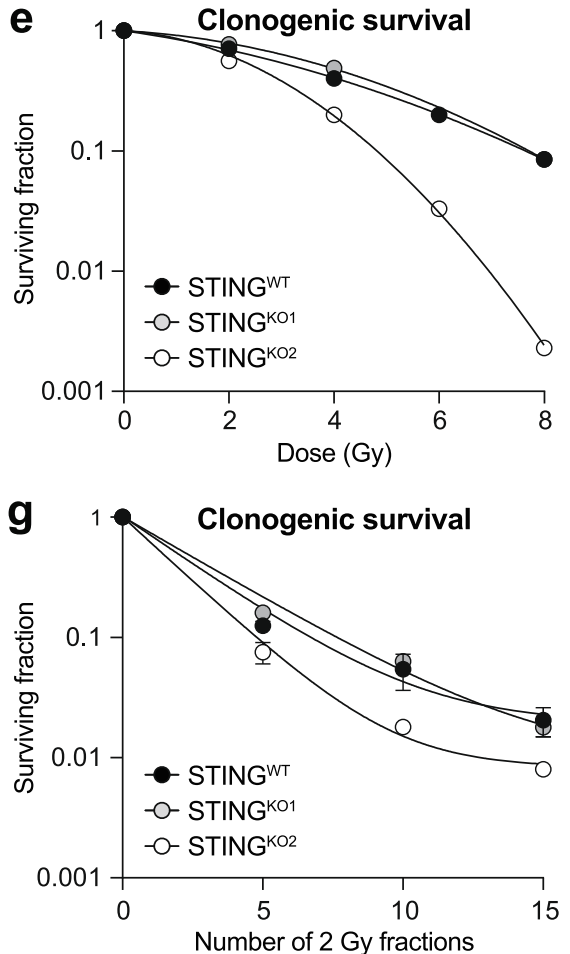

IFIT1

IFIT2

IFI44

h

IFN- $\beta$

MX1

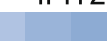

STINGWT
STING

STING ${ }^{\text {KO2 }}$

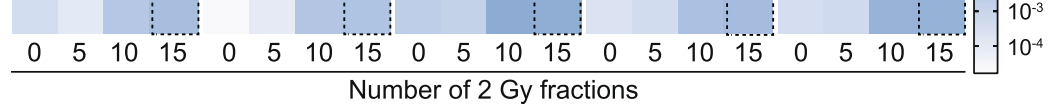

Fig. 4 (See legend on next page.) 


\section{(See figure on previous page.)}

Fig. 4 ISG induction upon fractionated irradiation occurs independent of STING, IFN- $\beta$ or IFN- $\lambda$. Interferon stimulated genes (ISGS) can be induced independent of the interferons known to mediate this response, or the upstream regulator protein STING. a mRNA expression levels of cGAS (grey bars) and STING (black bars) in different cancer cell lines. b Western blots showing protein expression of cGAS and STING in different cancer cell lines. Actin staining was used as loading control. The dotted box shows the only cell line, i.e. HT29, in which both cGAS and STING protein expression could be detected. c Heat map of mRNA expression of different ISGs and IFN- $\beta$ in HT29 cells treated with fractionated irradiation in the presence or absence of either anti IFN- $\beta$ antibody, anti IFN- $\lambda$ antibody or a STING antagonist. No significant changes were observed in the presence of any of the treatments as compared to irradiation alone $(n=3)$. $\mathbf{d}$ Clonogenic survival of HT29 during fractionated irradiation in the presence or absence of either anti IFN- $\beta$ antibody, anti IFN- $\lambda$ antibody or a STING antagonist. No significant changes in surviving fractions were observed in the presence of any of the latter treatments as compared to irradiation alone $(n=3)$. e Clonogenic survival of HT29 wild-type cells and two HT29 STING knockout cells in response to single dose irradiation. STING ${ }^{\mathrm{KO}}$ shows higher radiosensitivity as compared to wild type cells. f Cell numbers of HT29 wild-type cells and two HT29 STING knockout cells during fractionated irradiation. While STING ${ }^{\mathrm{KO} 2}$ displayed slower growth already at base-line, fractionated irradiation did not affect growth of knockout cells compared to wild type cells. $\mathbf{g}$ Clonogenic survival of HT29 wild-type cells and two HT29 STING knockout cells during fractionated irradiation. STING ${ }^{\mathrm{KO} 2}$ shows higher radiosensitivity as compared to wild type cells. h) Heat map of mRNA expression of different ISGs and IFN- $\beta$ in HT29 wild-type cells and two HT29 STING knockout cells during fractionated irradiation $(n=2)$. At baseline $(0 \times 2 \mathrm{~Gy})$ both knockout cell lines show lower expression of all genes analyzed as compared to wildtype cells. At the end of the treatment period $(15 \times 2 \mathrm{~Gy}$, dotted box) no more difference in expression levels is observed in wild-type vs.

knockout cells for any of the genes analyzed

response that is triggered by fractionated irradiation occurs independent of cGAS/STING signaling or induction of IFN expression.

Since our findings are different from the previously published role of STING in the response to radiotherapy and could be due to minimal undetected levels of STING, we also generated HT29 STING knockout cells using CRISPR/Cas gene editing. In 8 out of 10 single cell clones, knockdown could be confirmed by Western Blot (Supplementary Fig. S8a). Two clones were selected for further analysis and DNA sequencing confirmed gene editing at the expected location in exon 6 , causing a frameshift with two adjacent premature stop codons (Supplementary Fig. S8b). Interestingly, one of the STING knockout clones showed a phenotype similar to the wild type cells while the other knockout clone showed reduced cell growth (data not shown) and increased radiosensitivity (Fig. 4e). This clonal difference in growth and radiosensitivity was further illustrated when both clones were subjected to fractionated irradiation for 3 weeks (Fig. $4 \mathrm{f}+\mathrm{g}$ ). Despite these differences in phenotype, both knockout cell lines showed a similar, albeit delayed, induction of ISG expression as compared to the wild type cells (Fig. 4h). The latter suggests that STING, while it contributes to the induction of a type I IFN response during fractionated irradiation, is not essential for this response to occur. Altogether, STING, IFN- $\beta$ as well as IFN- $\lambda$ appear to be dispensable for activation of a type I IFN response during fractionated irradiation.

\section{Discussions}

In this study we demonstrate that a commonly applied clinical schedule of conventional low-dose fractionated irradiation (daily fractions of $2 \mathrm{~Gy}$ for 5 days per week, up to 6 weeks) induces an intrinsic type I interferon (IFN) response in tumor cells that is characterized by an increased expression of interferon stimulated genes (ISGs). The response peaks within 3 weeks of treatment and coincides with a convergence to a plateau in clonogenic survival in vitro and treatment resistance in vivo. It also occurs in tumor tissues from esophageal cancer patients during chemoradiotherapy. Importantly, the type I IFN response can be induced independently of a specific type I IFN or of STING-mediated signaling. Collectively, these findings suggest a potential clinical benefit of targeting specific type I interferon response genes (ISGs), irrespective of targeting STING or type I interferons during fractionated low-dose radiotherapy.

The induction of a type I IFN response by fractionated irradiation has been described previously in cancer cells of different origin. For example, using either breast cancer cells, prostate cancer cells or gliosarcoma cells Tsai et al. found significant induction of several ISGs after $5 \times 2$ Gy while $1 \times 10$ Gy did not trigger expression [9] . This was repeatedly confirmed by another group that described a more prominent induction of ISGs in prostate cancer cells after fractionated irradiation $(10 \times 1 \mathrm{~Gy})$ as compared to single dose $(1 \times 10 \mathrm{~Gy})$ irradiation [2224]. More recently, Vanpouille-Box et al. reported increased expression of ISGs in different mouse and human breast cancer cells after fractionated irradiation $(3 \times 8 \mathrm{~Gy})$, but not after single dose irradiation $(1 \times 20$ Gy) [10]. Our current data are in line with all these in vitro findings and confirm that the response is triggered in in vivo as well, albeit to a somewhat lesser extent $[9,10]$. Importantly, we show that the response becomes particularly activated after 2 weeks of radiotherapy and remains highly activated throughout the course of treatment. Together with the observation that the response is activated during fractionated radiotherapy in esophageal cancer patients, these findings suggest a potential clinical relevance of type I IFN signaling in the response to treatment. In line with this, the induction of 
type I interferons as well as other molecules by radiotherapy has been shown to elicit an anti-tumor immune response [4, 25]. At the same time, radiotherapy can hamper an adequate immune response which, together with the potential immune induction, has spurred interest to combine radiotherapy with immunotherapy, particular with checkpoint inhibitors [4, 25, 26]. Regarding the direct combination of radiotherapy with type I IFNs, the outcomes of clinical trials have been ambiguous and increased toxicity frequently led to negative recommendations on this treatment approach [16]. Possibly, this is related to inadequate dose-scheduling of both treatment modalities as radiation dose and scheduling have been shown to affect the immunostimulatory activity [26]. Our current findings indeed suggest that there is no rational for prolonged administration of IFNs or STING agonists during radiotherapy, particularly if this results in increased toxicity. At the same time, to boost antitumor immune responses, IFNs or STING-agonists might be beneficial but only when administered briefly, i.e., in the first weeks of fractionated radiotherapy. Future studies should thus focus on optimal dosescheduling of radiotherapy in combination with type I IFN-targeted treatment.

Apart from therapeutic options, the observed type I IFN expression signature could also have diagnostic/ prognostic value. Previously, an IFN-related DNA damage resistance signature (IRDS) has been found to be predictive for poor survival outcome in GBM patients [18] as well as for the efficacy of adjuvant chemotherapy and local-regional control after radiation in breast cancer patients [19]. Although we could not confirm the latter in our patient series due to the small sample size, it can be speculated that the observed induction of a type I IFN response in our patient group during (chemo) radiotherapy serves as a radioprotective mechanism. This is supported by our finding that the peak in ISG expression after 2 weeks of irradiation coincides with the convergence to a plateau in clonogenic survival [11]. On the other hand, Guggenberger et al. described that 4 weeks of fractionated low-dose irradiation (daily dose of 0.5 or $1.0 \mathrm{~Gy}$ ) of primary cultures of benign prostate epithelial cells resulted in downregulation of a type I interferon expression signature [27]. Interestingly, the expression analyses in that study were performed 1 week after completion of the fractionated irradiation schedule. Apart from differences in fraction dose and cell type, this difference in timing of expression analysis most likely accounts for the discrepancy between both observations. In fact, a normalization or downregulation of the IFN response in the days or weeks after therapy supports our previous observation that fractionated irradiation induces transient and reversible radioresistance rather than acquired radioresistance [11]. This reversal or 'normalization' of the response should be further investigated, especially in the context of clinical samples, as it could provide therapeutic opportunities.

Although we observed that fractionated irradiation consistently induced expression signatures that are characteristic of a type I IFN response, there was no clear association with the expression of a specific type I IFN. Generally, antigen-presenting cells are considered as the main source of type I IFNs although intrinsic cancer cell production has been demonstrated after anthracyclinebased chemotherapy [28] and radiotherapy [10]. In line with this, we did observe that irradiation can induce IFN- $\beta$ or IFN- $\lambda$ expression in cancer cells $[17,20,29]$. However, the induction did not occur in all cell lines even though downstream ISG expression was always triggered. Furthermore, blocking either IFN- $\beta$ or IFN- $\lambda$ did not affect the induction of ISGs during fractionated irradiation. This contradicts studies that have shown that the induction of a type I IFN response does not occur in cells that lack IFNAR1 (Interferon Alpha and Beta Receptor Subunit 1) expression. Since we did not block IFNAR1 or any of the other IFN receptors, we cannot rule out that other IFN family members might be responsible for the induction of ISG expression. While this could be further explored, our data still indicate that neither IFN- $\beta$ nor IFN- $\lambda$ are required for the induction of a type I IFN response during fractionated irradiation.

Of note, a mechanism that has been proposed to prevent the induction of the type I IFN response involves induction of the DNA exonuclease Three Prime Repair Exonuclease 1 (TREX1) [10]. This protein was found to degrade cytosolic DNA that accumulates in irradiated cancer cells, thereby impeding a type I IFN response [10]. It has been shown that this mechanism is triggered after single high dose (>12-18 Gy) irradiation and not after fractionated irradiation $(3 \times 8 \mathrm{~Gy})$ [10]. Interestingly, Erdal et al. linked accumulation of cytosolic DNA in TREX1-deficient human breast cancer cells and mouse embryonic fibroblast cells to increased radioresistance and ISG signaling after a single dose of 6 to $10 \mathrm{~Gy}$. Disrupting the downstream transcription factor interferon regulatory factor 3 (IRF-3) in these cells completely abolished ISG induction and the observed radioresistance. Although we cannot rule out involvement of TREX1 in cancer cells that do not show increased IFN expression after fractionated irradiation with 2 Gy (Colo320 and SW480), these cells still showed induction of ISG expression and a steady state in clonogenic survival [11].

The disconnection between specific type I or type III IFN expression and the induction of ISG expression is further supported by our finding that the response also occurs in cancer cells that lack either cGAS (cyclic GMP-AMP Synthase) or STING (Stimulator of 
interferon genes) expression. It has been shown that the cGAS/STING signaling axis is a key regulator of the innate immune response [21, 30,31]. This pathway also triggers type I IFN expression in response to DNA damage $[10,14,17,29]$. Indeed, several studies have described that inhibition or complete knockout of either cGAS or STING hampers an adequate type I IFN response in vitro and in vivo $[10,14,17,29,32]$. In contrast, we observed comparable induction of ISGs during fractionated irradiation of cancer cell lines, irrespective of cGAS or STING expression. Also, treatment with a STING antagonist or knockout of STING could not prevent ISG expression induction. However, we did observe a delay in expression induction in the absence of STING in HT29 STING-knockout cells. Apparently, STING facilitates or contributes to the activation of ISG expression during the early phase of fractionated irradiation, but it is not indispensable. Our observation also implies that other pathways contribute to the activation of ISG expression. In that regard, pattern-recognition receptors, such as Toll-like receptors, (TLRs) are known to activate innate type I IFN signaling [33] and agonists of TLRs can improve the response to radiotherapy [34, 35]. On the other hand, it has previously been demonstrated that key downstream adapter molecules of TLR signaling, like Myeloid Differentiation primary-response protein 88 (MyD88) and TIR-domain-containing adaptor protein inducing IFN- $\beta$ (TRIF), are not essential to induce a type I IFN response during radiotherapy [14]. Interestingly, RNA activated innate immune pathways controlled by RIG-I (retinoic acid-inducible gene I) and MDA5 (melanoma differentiation-associated protein 5) are significantly less affected by loss-of-function mutations or epigenetic silencing as compared to STING [36] and can be linked type I IFN signaling in a STING-independent manner. RIG-I and MDA-5, triggered by either RNA from dying neighboring cells or production of small cytosolic RNA fragments via RNA Polymerase III [37, 38], could elicit a similar set of transcription factors involved in expression of type I IFNs via Mitochondrial Antiviral-Signaling protein (MAVS). Also, other cytosolic DNA sensors, e.g. IFI16 and DDX41, might play a role as extensively reviewed recently [39]. The interplay between such cytosolic DNA/RNA sensing mechanisms in controlling type I IFN signaling during (fractionated) irradiation should be further studied.

Finally, the exact role of type I IFN signaling in the response to radiotherapy should be further explored. As recently reviewed by us and others, type I IFNs can exert both intrinsic and extrinsic anti-tumor effects. This includes inhibition of cell growth and migration, induction of apoptosis and senescence, and activation of $\mathrm{T}$-cell mediated immunity $[16,40]$. As such, the induction of a type I IFN response during fractionated irradiation could be considered as beneficial. At the same time, as described above, combining type I IFN treatment with radiation therapy in the clinic has been met with increased toxicity and limited or no clinical benefit [16]. In addition, high tumoral expression of ISGs or upstream transcription factors like STAT1 (Signal Transducer and Activator of Transcription 1) are indicators of radioresistance and a predictor of poor patient survival [18, 19, 41, $42]$. We also observed an elevated type I IFN response in cancer cells at the time they adopt a radiotolerant phenotype. Thus, activation of type I IFN signaling by DNA damaging agents like radiotherapy might not be beneficial at all [43].

\section{Conclusions}

In conclusion, our current findings indicate that clinically applied fractionated low-dose irradiation triggers expression of type I IFN stimulated genes independent of interferons or STING-mediated signaling. While the exact underlying mechanism needs to be resolved, our data provide novel insights in the relevance of the type I interferon response and STING signaling during lowdose fractionated irradiation which are relevant for current efforts that aim to target this response in the context of combination radiotherapy. In particular, the timing of type I IFN-targeted treatment during radiotherapy should be carefully explored as it might induce beneficial and detrimental effects depending upon a delicate balance between responses within the tumor microenvironment, including but not restricted to STING signaling pathway capacity.

\section{Abbreviations}

CGAS: Cyclic GMP-AMP Synthase; CRT: Chemoradiotherapy; DDX41: DEADbox helicase 41; DMEM: Dulbecco's Modified Eagle Medium;

GBM: Glioblastoma Multiforme; GO: Gene Ontology; IFI16: Interferon gamma Inducible protein 16; IFN: Interferon; IFN-a: Interferon alpha; IFN- $\beta$ : Interferon beta; IFN- $\lambda$ : Interferon lambda; IFNAR1: Interferon Alpha and Beta Receptor Subunit 1; IRF-3: Interferon Regulatory Factor 3; ISG: Interferon Stimulated Gene; MAVS: Mitochondrial Antiviral-Signaling protein; MDA5: Melanoma Differentiation-Associated protein 5; PTBK: phosphorylated Tank Binding Kinase; RIG-I: Retinoic acid-Inducible Gene l; RTx: Radiotherapy; STAT1: Signal Transducer and Activator of Transcription 1; STING: Stimulator of interferon genes; TREX1: Three prime Repair Exonuclease 1

\section{Supplementary Information}

The online version contains supplementary material available at https://doi. org/10.1186/s13046-021-01962-2.

\section{Additional file 1.}

Additional file 2.

\section{Acknowledgements}

Not applicable.

\section{Authors' contributions}

RG and EA wrote the manuscript and formatted figures. RG, EA, FB, KC, SH, $I S, L K$ and JB were involved in conducting experiments and data analysis. $M J$ and $A B$ provided patient samples. NG performed pathological assessment of 
patient samples. SD, BS, HV, AH and VT were involved in concept and supervision. The authors read and approved the final manuscript.

\section{Funding}

Not applicable.

\section{Availability of data and materials}

The datasets used and/or analyzed during the current study are available from the corresponding author on reasonable request.

\section{Declarations}

\section{Ethics approval and consent to participate}

All patient material was obtained after retrieval of informed consent in an IRB-approved clinical trial (NCT02072720 / METC-VUmc identifier 2013.340), approved by the Medical Ethics Review Committee of VU University Medical Center (registered with the US Office for Human Research Protections (OHRP) as IRB00002991)

\section{Consent for publication}

Not applicable.

\section{Competing interests}

The authors declare that the research was conducted in the absence of any commercial or financial relationships that could be construed as a potential conflict of interest.

\section{Author details}

'Department of Medical Oncology, Cancer Center Amsterdam, Amsterdam UMC, location VUmc, Amsterdam, The Netherlands. ${ }^{2}$ Oncode Institute, Utrecht, The Netherlands. ${ }^{3}$ Department of Molecular Oncology, University of Oxford, Oxford, UK. ${ }^{4}$ Department of Radiation Oncology, Cancer Center Amsterdam, Amsterdam UMC, location VUmc, Amsterdam, The Netherlands. ${ }^{5}$ Department of Gastroenterology, Cancer Center Amsterdam, Amsterdam UMC, location VUmc, Amsterdam, The Netherlands. ${ }^{6}$ Department of Gastroenterology, Noord West Ziekenhuisgroep, Alkmaar, The Netherlands. ${ }^{7}$ Department of Pathology, Cancer Center Amsterdam, Amsterdam UMC, location VUmc, Amsterdam, The Netherlands. ${ }^{8}$ Department of Medical Oncology, Radboud UMC, Nijmegen, The Netherlands.

\section{Received: 17 February 2021 Accepted: 25 April 2021}

\section{Published online: 08 May 2021}

\section{References}

1. Bernier J, Hall EJ, Giaccia A. Radiation oncology: a century of achievements. Nat Rev Cancer. 2004;4(9):737-47. https://doi.org/10.1038/nrc1451.

2. Baumann M, Krause M, Hill R. Exploring the role of cancer stem cells in radioresistance. Nat Rev Cancer. 2008;8(7):545-54. https://doi.org/10.1038/ nrc2419.

3. Begg AC, Stewart FA, Vens C. Strategies to improve radiotherapy with targeted drugs. Nat Rev Cancer. 2011;11(4):239-53. https://doi.org/10.1038/ nrc3007.

4. Goedegebuure RSA, de Klerk LK, Bass AJ, Derks S, Thijssen VLJ. Combining radiotherapy with anti-angiogenic therapy and immunotherapy; a therapeutic triad for cancer. Front Immunol. 2019;9:3107.

5. Morgan MA, Lawrence TS. Molecular pathways: overcoming radiation resistance by targeting DNA damage response pathways. Clin Cancer Res. 2015:21(13):2898-904. https://doi.org/10.1158/1078-0432.CCR-13-3229.

6. Sharma RA, Plummer R, Stock JK, et al. Clinical development of new drugradiotherapy combinations. Nat Rev Clin Oncol. 2016;13(10):627-42. https:// doi.org/10.1038/nrclinonc.2016.79.

7. Ahn SJ, Choi C, Choi YD, Kim YC, Kim KS, Oh IJ, et al. Microarray analysis of gene expression in lung cancer cell lines treated by fractionated irradiation. Anticancer Res. 2014;34(9):4939-48.

8. Hennel R, Brix N, Seidl K, Ernst A, Scheithauer H, Belka C, et al. Release of monocyte migration signals by breast cancer cell lines after ablative and fractionated $y$-irradiation. Radiat Oncol. 2014;9(1):85. https://doi.org/10.11 86/1748-717X-9-85

9. Tsai M-H, Cook JA, Chandramouli GVR, DeGraff W, Yan H, Zhao S, et al. Gene expression profiling of breast, prostate, and Glioma cells following single versus fractionated doses of radiation. Cancer Res. 2007;67(8):3845-52. https://doi.org/10.1158/0008-5472.CAN-06-4250.

10. Vanpouille-Box C, Alard A, Aryankalayil MJ, Sarfraz Y, Diamond JM, Schneider RJ, et al. DNA exonuclease Trex1 regulates radiotherapy-induced tumour immunogenicity. Nat Commun. 2017;8(1):15618. https://doi.org/10.1038/ ncomms15618.

11. van den Berg J, Castricum KCM, Meel MH, Goedegebuure RSA, Lagerwaard FJ, Slotman BJ, et al. Development of transient radioresistance during fractionated irradiation in vitro. Radiother Oncol. 2020;148:107-14. https:// doi.org/10.1016/j.radonc.2020.04.014.

12. Kleibeuker EA, Fokas E, Allen PD, Kersemans V, Griffioen AW, Beech J, et al. Low dose angiostatic treatment counteracts radiotherapy-induced tumor perfusion and enhances the anti-tumor effect. Oncotarget. 2016;7(47): 76613-27. https://doi.org/10.18632/oncotarget.12814.

13. Lamble S, Batty E, Attar M, Buck D, Bowden R, Lunter G, et al. Improved workflows for high throughput library preparation using the transposomebased Nextera system. BMC Biotechnol. 2013;13(1):104. https://doi.org/10.11 86/1472-6750-13-104.

14. Deng L, Liang $H, X u$ M, Yang X, Burnette B, Arina A, et al. STING-dependent cytosolic DNA sensing promotes radiation-induced type I interferondependent antitumor immunity in immunogenic tumors. Immunity. 2014; 41(5):843-52. https://doi.org/10.1016/j.immuni.2014.10.019.

15. Wilkins AC, Patin EC, Harrington KJ, Melcher AA. The immunological consequences of radiation-induced DNA damage. J Pathol. 2019;247(5):60614. https://doi.org/10.1002/path.5232.

16. Goedegebuure RSA, Vonk C, Kooij LP, Derks S, Thijssen VLJL. Combining radiation therapy with Interferons: Back to the future. Int J Radiat Oncol Biol Phys. 2020;108(1):56-69. https://doi.org/10.1016/j.ijrobp.2020.02.016. Epub 2020 Feb 14.

17. Chen J, Markelc B, Kaeppler J, Ogundipe VML, Cao Y, McKenna WG, et al. STING-dependent interferon- $\lambda 1$ induction in HT29 cells, a human colorectal cancer cell line, after gamma-radiation. Int J Radiat Oncol Biol Phys. 2018; 101(1):97-106. https://doi.org/10.1016/j.jirobp.2018.01.091

18. Duarte CW, Willey CD, Zhi D, Cui X, Harris JJ, Vaughan LK, et al. Expression signature of IFN/STAT1 signaling genes predicts poor survival outcome in glioblastoma multiforme in a subtype-specific manner. PLoS One. 2012;7(1): e29653. https://doi.org/10.1371/journal.pone.0029653.

19. Weichselbaum RR, Ishwaran H, Yoon T, Nuyten DSA, Baker SW, Khodarev N, et al. An interferon-related gene signature for DNA damage resistance is a predictive marker for chemotherapy and radiation for breast cancer. Proc Natl Acad Sci U S A. 2008;105(47):18490-5. https://doi.org/10.1073/pnas. 0809242105.

20. Burnette BC, Liang H, Lee Y, Chlewicki L, Khodarev NN, Weichselbaum RR, et al. The efficacy of radiotherapy relies upon induction of type i interferondependent innate and adaptive immunity. Cancer Res. 2011;71(7):2488-96. https://doi.org/10.1158/0008-5472.CAN-10-2820.

21. Ishikawa H, Ma Z, Barber GN. STING regulates intracellular DNA-mediated, type I interferon-dependent innate immunity. Nature. 2009;461(7265):78892. https://doi.org/10.1038/nature08476.

22. Simone CB, John-Aryankalayil M, Palayoor ST, et al. mRNA expression profiles for prostate cancer following fractionated irradiation are influenced by p53 status. Transl Oncol. 2013;6(5):573-85. https://doi.org/10.1593/ tlo.13241.

23. John-Aryankalayil M, Palayoor ST, Cerna D, Simone CB II, Falduto MT, Magnuson SR, et al. Fractionated radiation therapy can induce a molecular profile for therapeutic targeting. Radiat Res. 2010;174(4):446-58. https://doi. org/10.1667/RR2105.1

24. Aryankalayil MJ, Makinde AY, Gameiro SR, Hodge JW, Rivera-Solis PP, Palayoor ST, et al. Defining molecular signature of pro-immunogenic radiotherapy targets in human prostate cancer cells. Radiat Res. 2014;182(2): 139-48. https://doi.org/10.1667/RR13731.1.

25. Weichselbaum RR, Liang H, Deng L, Fu YX. Radiotherapy and immunotherapy: a beneficial liaison. Nat Rev Clin Oncol. 2017;14(6):365-79. https://doi.org/10.1038/nrclinonc.2016.211.

26. Gandhi SJ, Minn AJ, Vonderheide RH, Wherry EJ, Hahn SM, Maity A. Awakening the immune system with radiation: optimal dose and fractionation. Cancer Lett. 2015;368(2):185-90. https://doi.org/10.1016/j.ca nlet.2015.03.024

27. Guggenberger F, van de Werken HJG, Erb HHH, Cappellano G, Trattnig K, Handle $F$, et al. Fractionated radiation of primary prostate basal cells results in 
downplay of interferon stem cell and cell cycle checkpoint signatures.[letter]. Eur Urol. 2018;74(6):847-9. https://doi.org/10.1016/j.eururo.2018.06.002

28. Sistigu A, Yamazaki T, Vacchelli E, Chaba K, Enot DP, Adam J, et al. Cancer cell-autonomous contribution of type I interferon signaling to the efficacy of chemotherapy. Nat Med. 2014;20(11):1301-9. https://doi.org/10.1038/ nm.3708.

29. Härtlova A, Erttmann SF, Raffi FA, et al. DNA damage primes the type interferon system via the cytosolic DNA sensor STING to promote antimicrobial innate immunity. Immunity. 2015;42(2):332-43. https://doi.org/10.1 016/j.immuni.2015.01.012.

30. Ishikawa H, Barber GN. STING is an endoplasmic reticulum adaptor that facilitates innate immune signalling. Nature. 2008;455(7213):674-8. https:// doi.org/10.1038/nature07317.

31. Sun L, Wu J, Du F, Chen X, Chen ZJ. Cyclic GMP-AMP synthase is a cytosolic DNA sensor that activates the type I interferon pathway. Science. 2013; 339(6121):786-91. https://doi.org/10.1126/science.1232458.

32. Erdal E, Haider S, Rehwinkel J, Harris AL, McHugh PJ. A prosurvival DNA damage-induced cytoplasmic interferon response is mediated by end resection factors and is limited by Trex1. Genes Dev. 2017;31(4):353-69. https://doi.org/10.1101/gad.289769.116.

33. Akira S, Takeda K. Toll-like receptor signalling. Nat Rev Immunol. 2004;4(7): 499-511. https://doi.org/10.1038/nri1391.

34. Apetoh L, Ghiringhelli F, Tesniere A, Obeid M, Ortiz C, Criollo A, et al. Tolllike receptor 4-dependent contribution of the immune system to anticancer chemotherapy and radiotherapy. Nat Med. 2007;13(9):1050-9. https://doi. org $/ 10.1038 / \mathrm{nm} 1622$.

35. Dovedi SJ, Melis MHM, Wilkinson RW, Adlard AL, Stratford IJ, Honeychurch J, et al. Systemic delivery of a TLR7 agonist in combination with radiation primes durable antitumor immune responses in mouse models of lymphoma. Blood. 2013;121(2):251-9. https://doi.org/10.1182/blood-201205-432393.

36. Konno H, Yamauchi S, Berglund A, Putney RM, Mulé JJ, Barber GN. Suppression of STING signaling through epigenetic silencing and missense mutation impedes DNA damage mediated cytokine production. Oncogene. 2018;37(15):2037-51. https://doi.org/10.1038/s41388-017-0120-0.

37. Chiu YH, Macmillan JB, Chen ZJ. RNA polymerase III detects cytosolic DNA and induces type I interferons through the RIG-I pathway. Cell. 2009;138(3): 576-91. https://doi.org/10.1016/j.cell.2009.06.015.

38. Ablasser A, Bauernfeind F, Hartmann G, Latz E, Fitzgerald KA, Hornung V. RIG-I-dependent sensing of poly (dA:dT) through the induction of an RNA polymerase III-transcribed RNA intermediate. Nat Immunol. 2009;10(10): 1065-72. https://doi.org/10.1038/ni.1779.

39. Vanpouille-Box C, Demaria S, Formenti SC, Galluzzi L. Cytosolic DNA sensing in organismal tumor control. Cancer Cell. 2018;34(3):361-78. https://doi. org/10.1016/j.ccell.2018.05.013.

40. Parker BS, Rautela J, Hertzog PJ. Antitumour actions of interferons: implications for cancer therapy. Nat Rev Cancer. 2016;16(3):131-44. https:// doi.org/10.1038/nrc.2016.14.

41. Khodarev NN, Beckett M, Labay E, Darga T, Roizman B, Weichselbaum RR. STAT1 is overexpressed in tumors selected for radioresistance and confers protection from radiation in transduced sensitive cells. Proc Natl Acad Sci U S A. 2004;101(6):1714-9. https://doi.org/10.1073/pnas.0308102100.

42. Pitroda SP, Wakim BT, Sood RF, Beveridge MG, Beckett MA, MacDermed DM, et al. STAT1-dependent expression of energy metabolic pathways links tumour growth and radioresistance to the Warburg effect. BMC Med. 2009; 7(1):68. https://doi.org/10.1186/1741-7015-7-68

43. Cheon $\mathrm{H}$, Borden EC, Stark GR. Interferons and their stimulated genes in the tumor microenvironment. Semin Oncol. 2014;41(2):156-73. https://doi.org/1 0.1053/j.seminoncol.2014.02.002.

\section{Publisher's Note}

Springer Nature remains neutral with regard to jurisdictional claims in published maps and institutional affiliations.

\section{Ready to submit your research? Choose BMC and benefit from:}

- fast, convenient online submission

- thorough peer review by experienced researchers in your field

- rapid publication on acceptance

- support for research data, including large and complex data types

- gold Open Access which fosters wider collaboration and increased citations

- maximum visibility for your research: over $100 \mathrm{M}$ website views per year

At BMC, research is always in progress.

Learn more biomedcentral.com/submissions 